\title{
Study of the Process Motivation Theory for Improving the Learning Autonomy in Shaanxi Private College Students
}

\author{
Hua Hui \\ Shaanxi Institute of International Trade and Commerce, Xianyang, Shaanxi, 712046
}

\begin{abstract}
The construction of the style of study is an significant issue for the cultivation of talents in China. The importance and significance is self-evident. In the private colleges in shaanxi province, the problem in the construction of the style of study is especially prominent. The key source to solve this problem is to improve the learning autonomy among the college students. In this paper, research is carried out on five representing private colleges. The results are analyzed and the data of the students learning autonomy is obtained, the problem is decomposed. At last, countermeasures and suggestions to the point are proposed combining with the theory of process motivation.
\end{abstract}

Key Words: Private College Students, Style of Study Construction, Learning Autonomy, Process Motivation, Hoist Way.

\section{Introduction}

Shaanxi is one of the provinces where the development of private colleges is most powerful. Up to the year 2012, there are 18 private colleges in Shaanxi. Among them, there are eight private colleges for undergraduate education with ten for vocational and technical education. The fixed assets in schools accumulates more than seven point one billion Yuan. It can be seen that the private education enterprise has become one of the main forces in the development of higher education in Shaanxi. The own special system, students and position of private colleges determines the urgency and difficulty in the construction of study style.

The style of study is one of the key factors that affect the connotation development and quality construction in the colleges and universities. The construction of the style of study is directly related to the quality of talents cultivation. In the private colleges in Shaanxi, the studying style construction has always been included into the focus of education and teaching work. However, the problem of studying style construction has been a perplexity in the development of private colleges, even becomes a stumbling block to the educational quality improvement. The cause of this problem has a direct relation with the failure for the colleges to find the origins of the problem. Most of the students in private colleges fail to get a high score in the college entrance examination. The comprehensive quality index of these students is in the low side and the awareness of study is not high, causing the phenomena of study detestation and study abandonment, which furthermore brings harmful impacts on the style of study. Therefore, the key lies in finding out the causes and prosing targeted methods. It comes down to develop the enthusiasm and initiative in study and to cultivate autonomous learning, which has realistic meaning for the construction of study style in Shaanxi province.

\section{Connotation of Learning Autonomy}

Cultivating learning autonomy is an important segment in comprehensively promote quality education in China. It can break the previous passive studying scheme(like cramming education) and cultivate new type of talents who have voluntary development desire, lifelong studying ability and can adapt to the knowledge and economic development. To obtain a deep understanding of the connotation of learning autonomy is beneficial to solve the study style construction problem in Shaanxi province.

Zimmerman, an American scholar, put forward that if the learners have the ability of actively applying meta cognition learning strategies and can stimulate learning motivation and can actively make self observation, self judgment and self reaction to their own learning behavior, then their learning belongs to autonomous learning. In addition, he believes that the autonomy of the study depends on the six aspects of the answer to the questions, that is, "why? How? When? What? Where? 
and with Whom?". These six questions practically show the studying intention (self motivation), strategy arrangement, time management, learning targets setting, studying atmosphere and role models choice of the learners.

\section{Investigation Results}

\subsection{Overall Situation of Learning Autonomy of Private Colleges Students in Shaanxi}

Through analysis, the average score of learning autonomy of private colleges students in Shaanxi is 2.78 points, belonging to the mediocre level, as is shown in table 1 . Among the five aspects, studying strategy, time management and targets have lower averaged scores, while motivation and atmosphere have higher averaged scores.

table 1. Overall level of learning autonomy of private colleges students in Shaanxi

\begin{tabular}{|c|c|c|c|c|c|}
\hline Items & $\begin{array}{c}\text { Motivatio } \\
\mathrm{n}\end{array}$ & Strategy & $\begin{array}{c}\text { Time } \\
\text { management }\end{array}$ & Targets & Atmosphere \\
\hline Averaged scores & 3.22 & 2.83 & 2.74 & 2.67 & 3.39 \\
\hline Standard deviation & 0.74 & 0.76 & 0.72 & 0.78 & 0.70 \\
\hline Rank & 2 & 3 & 4 & 5 & 1 \\
\hline
\end{tabular}

\subsection{Gender Differences in Learning Autonomy of Private Colleges Students in Shaanxi}

From table 2, there exist gender differences in learning autonomy of private colleges students in Shaanxi. Relatively, the female college students are better in the motivation, strategy, management and atmosphere than the male college students, which shows that the female students have more positive and active attitudes towards studying.

table 2. Gender differences in learning autonomy of private colleges students

in Shaanxi

\begin{tabular}{|c|c|c|c|}
\hline Items & $\begin{array}{c}\text { Male }(\mathrm{n}=282) \\
\left(\mathrm{M} \pm_{\mathrm{SD}}\right)\end{array}$ & $\begin{array}{c}\text { Female(n=207) } \\
\left(\mathrm{M} \pm_{\mathrm{SD}}\right)\end{array}$ & \\
\hline Motivation & $3.20 \pm_{0.77}$ & $3.24 \pm_{0.74}$ & 0.442 \\
\hline Strategy & $2.79 \pm_{0.74}$ & $2.87 \pm_{0.77}$ & -1.073 \\
\hline Time management & $2.60 \pm_{0.69}$ & $2.88 \pm_{0.73}$ & -1.133 \\
\hline Targets & $2.70 \pm_{0.83}$ & $2.64 \pm_{0.72}$ & 1.487 \\
\hline Atmosphere & $3.35 \pm_{0.63}$ & $3.43 \pm_{0.76}$ & 1.239 \\
\hline Whole questionnaire & $2.64 \pm_{0.63}$ & $2.66 \pm_{0.63}$ & -0.098 \\
\hline
\end{tabular}

\subsection{The Current Situation Analysis of Learning Autonomy of Private Colleges Students in} Shaanxi

Combining the research results, it is easy to find that overall the private college students in Shaanxi province have quite certain management and choice of studying motivation and atmosphere, while having not enough attention to studying strategy, time management and targets. It causes the decrease of learning efficiency and furthermore leads to the phenomena of study detestation and study abandonment, as is shown in table.1. Besides, through the investigation, most students are not interested in the knowledge the teachers teach at class, thinking the knowledge is not beneficial for improving the adapting ability to the society or major ability and has little practical use. Even some of the students think that the study is only for the graduation certificate to add their value or act as a key to the success. Therefore, they have negative attitudes towards studying.

As is shown in table.2, in the process of investigation on the studying targets of private college students, the first choice of the targets is to find a good job, while to raise the competitive power and learn knowledge and ability rank second and third. It can be seen the correlation between the study and the career is more of concern among private college students in Shaanxi. This factor is the key breakthrough in raising learning autonomy of private college students in Shaanxi. 


\section{Mechanism Analysis of Raising Learning Autonomy of Private College Students in Shaanxi}

\subsection{Overall View of Process Based Motivation Theory}

The process based theory put focus on the whole procedure of how to produce the human behaviors, how the behaviors develop in certain directions, how to keep the human behaviors and how to end the human behaviors. Combined with the needs of this research, evaluation suggestions are proposed combining the Forum's expectation theory, Rock's theory of goal setting and Skinner's reinforcement theory.

\subsection{Countermeasures and Suggestions of Raising Learning Autonomy of Private College Students in Shaanxi}

Comparing to the students of public universities, the students in private colleges relatively lack comprehensive quality, knowledge foundation and learning autonomy. Therefore, the patterns and methods public universities apply in teaching and talents cultivation are not suitable for the private colleges. Combined with the above analysis and the process of incentive theory, the paper puts forward the following suggestions for the improvement of private college students' learning autonomy in Shaanxi.

\subsubsection{The Curriculum Should be Mainly Based on Practical Courses, Focusing on the Integration of Courses}

Through this investigation of five representing private colleges in Shaanxi province, it can be seen that the private college students pay extreme attention to the social practical use of the knowledge and the study of practical skills. Thirty-nine percent of the students set finding good jobs as studying targets. However, the traditional course can not attract the attention of the students and can not promote the interest of the students for learning autonomously. Therefore, it has serious influence on the quality of the courses and learning autonomy.

The percentage of practical courses in the major courses should be added in the private colleges in Shaanxi province. The teaching of the teachers should be less than one third and the teaching process should be combined with novel teaching methods as case teaching method, modular teaching, multimedia teaching, flipping the classroom and so on. The correlation to the practical matters should be reinforced by combining the current business market and enterprises. The teachers can set studying targets in the process of teaching according to each module. Setting reasonable studying goals and making students fulfill targets by self examining and self practicing can not only raise the valance in the studying stage, but also enhance the expectation in studying this knowledge. The power of motivation can be greatly developed. Otherwise, attention to the combination of knowledge should be paid when setting traditional courses. The traditional independent curriculum can be used as a module of transactional curriculum, and the force of students' learning is driven by the form of task, which can avoid the phenomena of cramming teaching and not much knowledge remain.

\subsubsection{Improve the Motivation and Feedback Mechanism for Students}

The goal setting theory not only proposes that the goal setting should be of proper difficulty, specific and clear, but also puts forward that the feedback on the working situation should be given to make the students have awareness of their own situation and improve their performance. The students should also participate in setting their targets which can get better results. The cultivation scheme should be set concerning the comprehensive quality level and specific requirement of students, such as whether a certain need to obtain the relevant qualification certificate in order to graduate or the proportion of final examination results. If necessary, advice should be sought from relevant professional students. Besides, comments and feedback should be given combining with the studying situation of students, which help students adjust the studying strategies and methods in time.

4.2.3Raise of Learning Autonomy Based on All kinds of competition, internship development certificate and learning achievement award

Combined with the theory of reinforcement theory, the positive reinforcement has significance in motivation. The private colleges should encourage students to participate in all kinds of specific competition in the process of opening relative courses. The participation of the competitions can not only stimulate students' active learning and exploration, but also can improve students' ability to solve practical problems. Meanwhile, the students can get material rewards. Besides, practice developing 
certificate can also accelerate the improvement of the ability of students to apply what they have learned, through the combination of school and enterprise, the certificate can be awarded to the students qualified with comprehensive quality and practical skills. The certificate can act as the certificate of priority in employment after graduation. Learning achievement award is mainly for the students who have excellent performance in study. Special material award should be provided as all kinds of scholarship, published papers with high quality (the school can set the level of the papers in advance), invention patents, and specific certificates (with proper difficulty). When applying these methods, colleges should pay attention to the variety of methods and use persistent motivation with proper difficulty.

\subsubsection{Reform the Traditional Examination System and Cancel the Judgment of Students Based on Scores}

The orientation of talents cultivating in private colleges should focus on the talents with skills and appliance. The traditional examination scheme can not fully represent the application and operation skills of the knowledge college students learned. Therefore, the examination focused on students should be set combined with the related professional talents training programs. The exams should focus on the application of the students' knowledge and the assessment of the ability to solve practical problems. The examination form can also be diversified and simplified, such as, practical courses can be finished by submitting the report on the research of the curriculum, planning and other forms; electronic commerce course assessment can be done with computers (machine operation). Even when the traditional examinations are carried out, the difficulty should be decreased and the proportion of objective questions should be increased to make students pass the exams easily and practice solidly. For example, the Shenzhen vocational and technical school has canceled the examinations in the form of paper in the thirteenth five years plan, it produces online examination involving five kinds of questions which are radio, judgment, connection, sorting and filling in the blanks.

\section{Conclusions}

By investigating the students from five private colleges, it can be seen that the foundation of raising the studying styles lies in enhancing the learning autonomy in students. The reason why the private college students have low learning autonomy is the mismatch of the private colleges and the characteristics or requirements of the students. The cultivation method of school can not promote the enthusiasm of the students, the psychological valence is low, therefore it can not play a very good role in motivation.

The private colleges should set reasonable curriculum structures and contents combined with own teaching features. The student feedback mechanism should be improved. The participation in all kinds of competitions, achievement of relative certificates and reform of examination scheme should be included into the cultivation of the talents, which can motivate the learning autonomy of the students to the max value and enhance the learning autonomy and education equality of private colleges in Shaanxi province.

\section{References}

[1]Christopher J. Lucas.American Higher Education[M].New York:St.Martin's Griffin, 2012.

[2]Svava Bjarnason, etc.A New Dynamic: Private Higher Education[R] .A Report

Prepared for the UNESCO 2012 World Conference on Higher Education, 2012.

[3]Craig Prichard\&Paul Trowler edited.Realizing Qualitative Research into Higher Education [M].Aldershot: Ashgate Publishing Limited,2014.

[4]Pan Suyan.How higher educational institutions cope with social change:the case of Tsinghua university,china[D].Unpublished doctoral dissertation at the University of Hong Kong,2013. 
[5] Herman G. van de Werfliorst \& Ruud Luijkx. Educational Field of Study and Social Mobility: Disaggregating Social Origin and Education. Sociology No.4.(1 August 2014).

[6]Janice L. Nath. The Roles of Case Studies in the Educational Field. International Journal of Case Method Research\&Application, No.3.(2011).

[7]Burton R.Clark. The Distinctive [2] Herman G. van de Werfliorst\&Ruud Luijkx. Educational Field of Study and Social Mobility: Disaggregating Social Origin and Education. Sociology,No.4.(1August 2012).

[8]Heinz Dieter Meyer, Brian Rowan. The New Institutionalism in Education: Advancing Research and Policy, SUNY Press,2012.

[9]Philip Altbach, Daniel Levy. Private Higher Education: A Global Revolution.Sense, 2013.

[10]Heinz Dieter Meyer, Brian Rowan.The New Advancing Research and Policy SLTNY Press, Institutionalism in Education:2014. 